p-ISSN 1693-9484, $e$-ISSN : 2621-8313

Majalah Ilmiah Bahari Jogja (MIBJ)

Vol. 18 No. 2, Juli $2020 \quad$ (1-7)

DOI : $10.33489 /$ mibj.v18i2.241

(C2020 Sekolah Tinggi Maritim Yogyakarta

\title{
Pengaruh Keaktifan Taruna di Kelas Terhadap Nilai Mata Kuliah Dasar- Dasar Akuntansi
}

\author{
Sulida Erliyana $^{{ }^{*}}$, Iik Suryati Azizah ${ }^{1}$, Evyana Diah Kusumawati ${ }^{1}$ \\ ${ }^{1}$ Program studi KPN, Politeknik Bumi Akpelni Semarang, Jl. Pawiyatan Luhur II/17, \\ Bendanduwur, Semarang. \\ * Corresponding Author. E-mail : sulida@akpelni.ac.id. Telp : +62 817-9501-990
}

\begin{abstract}
Abstrak
Penelitian ini bertujuan untuk mengetahui (1) hubungan keaktifan taruna di kelas dengan nilai mata kuliah dasar-dasar akuntansi di Politeknik Bumi Akpelni dan (2) bentuk keaktifan taruna di kelas saat perkuliahan dasar-dasar akuntansi. Populasi dalam penelitian ini adalah taruna KPN Politeknik Bumi Akpelni. Pengumpulan data dilakukan dengan metode kuesioner. Uji coba instrumen ini dilakukan terhadap 60 taruna program studi KPN dan digunakan analisis regresi sederhana. Terdapat asumsi-asumsi yang harus terpenuhi dalam analisis regresi. Asumsi-asumsi tersebut antara lain asumsi normalitas, heteroskedastisitas, multikolinieritas dan autokorelasi.Hasil penelitian ini adalah: (1) Terdapat pengaruh keaktifan taruna di kelas terhadap nilai mata kuliah dasar-dasar akuntansi di Politeknik Bumi Akpelni. Nilai mata kuliah dasar-dasar akuntansi dipengaruhi oleh keaktifan taruna di kelas sebesar 68,7\%. Sedangkan $31,3 \%$ dipengaruhi oleh faktor-faktor lainnya diluar penelitian ini. (2) Bentuk keaktifan taruna ketika kegiatan perkuliahan dasar-dasar akuntansi meliputi bertanya tentang materi yang diajarkan hingga aktif dalam memecahkan persoalan yang diberikan oleh dosen pengampunya.
\end{abstract}

Kata Kunci: taruna, keaktifan, nilai dasar-dasar akuntansi

\section{Abstract}

This study aims to find out (1) the relationship of active cadets in the classroom with the score of accounting basics courses in Polytechnic Bumi Akpelni and (2) the form of active cadets in the classroom during accounting basics courses. The population on this study is the KPN cadets of Polytechnic Bumi Akpelni. The data collection was carried out by using the questionnaire method. The trial of this instrument simple regression analysis was used and carried out by 60 cadets of the KPN study program. There are assumptions that it must be met in a regression analysis. These assumptions include normality, heteroscedasticity, multicollinearity and autocorrelation. The results of this study are: (1) There is a relationship between the activeness of cadets in the classroom and the score of accounting basics courses at the Polytechnic Bumi Akpelni. The score of accounting basics courses which influenced by the activeness of cadets in the classroom is $68.7 \%$. While $31.3 \%$ is influenced by the other factor of outside this study. (2) The form of active cadets when learning the basics accounting 
includes asking about the material being taught and being active in solving problems given by the lecturer.

Keywords: cadets, activeness, score of accounting basics courses

\section{PENDAHULUAN}

Perkembangan Sumber Daya Manusia (SDM) pada era globalisasi menuntut untuk terus mengembangkan dan meningkatkan ilmu pengetahuan dan teknologi supaya mampu bersaing dengan negara lain. Melalui pendidikan, diharapkan mampu membawa perubahan yang lebih baik demi tercapainya tujuan pendidikan nasional. Pendidikan merupakan proses pembentukan diri manusia secara menyeluruh, bukan hanya sekedar mentransfer ilmu pengetahuan tetapi mengupayakan bagaimana agar menjadi manusia yang bermoral baik, mandiri, tanggung jawab serta mampu menghadapi kehidupan dengan tetap bijaksana. Muhibbidin Syah (2015) berpendapat bahwa anggapan belajar adalah berhubungan dengan kesempatan yang diberikan kepada mahasiswa/taruna untuk berpartisipasi secara aktif dalam percakapan di kelas, maka cara mendistribusikan perhatian atau pertanyaan adalah hal yang penting.

Hasil belajar taruna adalah kemampuan yang diperoleh taruna setelah melalui kegiatan belajar. Salah satu faktor yang mempengaruhi hasil belajar yaitu keaktifan taruna di kelas (Astriawati and Wibowo, 2019). Menurut Irwanto (2015), dosen memiliki peranan penting dalam meningkatkan saling tukar pendapat antar taruna dengan dosen maupun taruna dengan taruna. Caranya dengan meminta taruna memberi komentar atau mengembangkan respon pertama. Kemudian dosen benar benar mau menerima dan membantu hasil sumbangan pemikiran taruna dan mengembangkan materi yang efektif untuk diberikan ke taruna(Astriawati, 2019).

Permasalahan mengenai rendahnya hasil belajar taruna di beberapa mata kuliah dan keaktifan taruna di kelas kurang mendapatkan perhatian dari dosen. Keaktifan bertanya taruna merupakan salah satu komponen penting dalam penilaian hasil belajar namun dosen maupun taruna belum menyadari hal tersebut. Peneliti berinsiatif melakukan penelitian tentang hubungan keaktifan taruna di kelas dengan nilai mata kuliah sebagai hasil belajar. Berdasarkan teori tersebut menunjukkan bahwa keaktifan taruna sangat erat hubungannya dengan hasil belajar sehingga dosen dapat lebih kreatif dalam mengaktifkan taruna terutama dalam bertanya.

Berdasarkan latar belakang masalah tersebut, maka peneliti akan mengkaji masalah tersebut dengan melakukan penelitian dengan judul Pengaruh Keaktifan Taruna di Kelas Terhadap Nilai Mata Kuliah Dasar-dasar Akuntansi di Politeknik Bumi Akpelni. 


\section{KAJIAN LITERATUR}

\section{Belajar}

Menurut Muhibbidin Syah (2015), belajar adalah suatu proses usaha yang dilakukan individu untuk memperoleh suatu perubahan tingkah laku yang baru secara keseluruhan sebagai hasil pengalaman individu itu sendiri dalam interaksi dengan lingkungannya. Menurut Setyowati (2016) bahwa belajar merupakan perubahan tingkah laku atau penampilan dengan serangkaian kegiatan. Kegiatan yang dimaksud misalnya seperti membaca, mengamati, mendengarkan, meniru, ataupun aktivitas individu dalam meningkatkan belajarnya.

\section{Prestasi Belajar}

Menurut Andika (2018) prestasi belajar merupakan tingkat kemanusiaan yang dimiliki siswa dalam menerima, menolak, dan menilai informasi-informasi yang diperoleh dalam proses belajar mengajar. Prestasi belajar dapat diketahui setelah melewati proses evaluasi yang diberikan oleh guru ataupun dosen. Hasil dari evaluasi tersebut dapat diketahui tinggi-rendahnya prestasi yang diperoleh.

\section{Penilaian Hasil Belajar Taruna}

Kegiatan yang diperoleh dari proses pendidikan merupakan faedah dari suatu pengalaman. Pengalaman yang diperoleh oleh taruna yaitu sebagai hasil belajar dari proses belajarnya selama satu semester. Penilaian terhadap studi taruna bertujuan untuk mengetahui tingkat penguasaan kompetensi yang telah dicapai seperti yang diharapkan. Penilaian yang dilakukan di Politeknik Bumi Akpelni melalui ujian serta nilai-nilai lain seperti tugas-tugas yang diberikan oleh dosen.

\section{METODE PENELITIAN}

\section{Tempat dan Waktu Penelitian}

Penelitian ini dilaksanakan di kampus Politeknik Bumi Akpelni Semarang, dengan waktu penelitian mulai dari bulan September 2019 sampai dengan bulan November 2019.

\section{Metode dan Desain Penelitian}

Metode yang digunakan dalam penelitian ini adalah metode kuantitatif dengan mengkaji hubungan antara keaktifan taruna di kelas terhadap nilai mata kuliah dasar-dasar akuntansi di Politeknik Bumi Akpelni. Uji statistik yang digunakan adalah Analisis Regresi Sederhana. Penelitian ini bertujuan untuk menjelaskan seberapa besar pengaruh variabel bebas yaitu keaktifan taruna $(x)$ terhadap nilai dasar-dasar akuntansi $(y)$.

\section{Populasi dan Teknik Pengambilan Sampel}

Populasi target dalam penelitian ini adalah taruna KPN Politeknik Bumi Akpelni Semarang. Teknik pengambilan sampel menggunakan teknik sampel purposive sampling. Purposive sampling adalah teknik pengambilan sampel sumber data dengan pertimbangan tertentu.

Alasan menggunakan teknik purposive sampling adalah karena tidak semua sampel memiliki kriteria yang sesuai dengan fenomena yang diteliti. Oleh karena 
itu, penulis memilih teknik purposive sampling yang menetapkan pertimbanganpertimbangan atau kriteria-kriteria tertentu yang harus dipenuhi oleh sampelsampel yang digunakan dalam penelitian ini. Dalam penelitian ini yang menjadi sampel yaitu taruna KPN Politeknik Bumi Akpelni Semarang yang mengambil mata kuliah dasar-dasar akuntansi pada semester genap tahun ajaran 2018/2019.

\section{Analisis Data}

Analisis data yang digunakan adalah analisis regresi sederhana (Sugiyono, 2015).

a. Model Analisis

$$
\hat{y}=a+b x
$$

dimana:

$y=$ Nilai dasar-dasar akuntansi

$x=$ keaktifan taruna

$\mathrm{b}=$ Intercept, yaitu titik potong antara garis regresi dengan sumbu tegak $y$

$\mathrm{a}=$ residual, yaitu selisih nilai respon yang sesungguhnya dengan nilai taksiran yang diperoleh dari model.

b. Tahapan Analisis

1. Analisis Regresi berganda dengan metode kuadrat terkecil klasik (Ordinary Least Square) untuk mengetahui seberapa besar keaktifan taruna di kelas mempengaruhi nilai mata kuliah dasar-dasar akuntansi.

2. Uji asumsi-asumsi agar diperoleh model yang konsisten dan efisien. Asumsi-asumsi tersebut diantaranya:

a. Multikolinearitas

Pada tahap ini dilihat nilai $\mathrm{R}^{2}$ (koefisien determinasi) dan nilai VIF (Variance inflation Factor) serta dilakukan uji individu terhadap parameter model. Apabila terjadi kasus multikolinieritas maka diselesaikan dengan regresi Stepwise (Stepwise regression).

b. Heterokedastisitas

Pada tahap ini, untuk mengetahuinya digunakan uji Glejser. Apabila ditemukan kasus heteroskedastisitas maka solusinya adalah melakukan transformasi terhadap variabel.

c. Autokorelasi

Pada tahap ini uji yang digunakan adalah uji Durbin Watson, namun selain itu juga dilihat dari plot ACF. Bila $95 \%$ nilai-nilai ACF tidak melebihi batas $\pm(1,96 / \sqrt{ } n)$, maka asumsi tidak ada autokorelasi terpenuhi.

d. Berdistribusi Normal

Untuk memeriksa kenormalan dapat digunakan uji KolmogorovSmirnov yaitu dengan membandingkan Pvalue statistic KolmogorovSmirnov dengan $\alpha=0,05$.

Setelah diperoleh model regresi yang sudah memenuhi beberapa asumsi klasik yang telah ditetapkan, maka dari model akhir tersebut dilakukan analisis dan kemudian dibuat kesimpulan. 


\section{HASIL DAN PEMBAHASAN}

\section{Uji Asumsi Klasik Analisis Regresi}

Uji asumsi klasik analisis regresi merupakan model regresi linier berganda dengan syarat-syarat yang harus dipenuhi pada regresi linier OLS agar model tersebut menjadi valid sebagai alat penduga.

a. Uji Normalitas

Tabel 1. Uji Kolmogorov-Smirnov

\begin{tabular}{lrcc}
\hline & \multicolumn{3}{c}{ Kolmogorov- } \\
& \multicolumn{3}{c}{ Smirnov } \\
\cline { 2 - 4 } & Statistic & df & Sig. \\
\hline $\begin{array}{l}\text { Unstandardize } \\
\text { d Residual }\end{array}$ &, 095 & 60 &, $200^{*}$ \\
\hline
\end{tabular}

Dari hasil uji normalitas pada Tabel 1 diketahui bahwa nilai signifikansi sebesar $0,200>0,05$, sehingga dapat disimpulkan residual menyebar normal.

b. Uji Heteroskedastisitas

Titik-titik tersebar secara acak dan tidak membentuk pola tertentu sehingga dapat disimpulkan bahwa tidak terjadi masalah heterokedastisitas pada model regresi.

c. Uji Multikolinieritas

Berdasarkan Tabel 2 diperoleh nilai Tolerance sebesar $1>0,1$ dan nilai VIF sebesar $1<10$. Sehingga dapat disimpulkan bahwa tidak terjadi multikolinieritas.

Tabel 2. Uji Multikolinieritas

\begin{tabular}{lcc}
\hline & \multicolumn{2}{c}{ Collinearity } \\
Model & Tolerance & VIF \\
\hline $\begin{array}{l}\text { (Constant) } \\
\text { keaktifan }\end{array}$ & 1,000 & 1,000 \\
\hline
\end{tabular}

d. Uji Autokorelasi

Nilai Durbin Watson sebesar 1,957 . Nilai tersebut berada diantara nilai du $=$ 1,6162 dan 4-du $=2,3838$, sehingga dapat disimpulkan bahwa tidak terjadi autokorelasi.

\section{Analisis Statistik Nilai Mata Kuliah Dasar-Dasar Akuntansi di Politeknik Bumi Akpelni}

a. Uji F

Uji ini dilakukan untuk mengetahui apakah model regresi yang digunakan cocok atau tidak. Hipotesis uji $\mathrm{F}$ adalah sebagai berikut:

$\mathrm{H}_{0}$ : Model regresi tidak cocok

$\mathrm{H}_{1}$ : Model regresi cocok

Pada taraf signifikansi sebesar $5 \% \mathrm{H}_{0}$ ditolak apabila nilai signifikansi yang diperoleh pada output uji $\mathrm{F}<0$. 
Tabel 3. ANOVA

\begin{tabular}{lrrrcr}
\hline & Sum of & & Mean & & \\
Model & Squares & df & Square & F & Sig. \\
\hline Regression & 7,792 & 1 & 7,792 & 127,126 &, 000 \\
Residual & 3,555 & 58 &, 061 & & \\
\hline Total & 11,346 & 59 & & &
\end{tabular}

Berdasarkan Tabel 3 dapat diketahui bahwa nilai signifikansi sebesar $0<0,05$ maka $\mathrm{H}_{0}$ ditolak sehingga pada taraf signifikansi 5\% model regresi yang dihasilkan cocok.

b. Uji T

Uji ini dilakukan untuk menguji apakah parameter-parameter yang digunakan signifikan terhadap model atau tidak. Hipotesisnya adalah sebagai berikut:

Ho: parameter tidak signifikan terhadap model

$\mathrm{H}_{1}$ : parameter signifikan terhadap model

Parameter dikatakan signifikan terhadap model apabila nilai signifikansi pada uji $\mathrm{t}<0,05$.

Tabel 4. Uji Signifikansi Parameter

\begin{tabular}{ccc} 
Model & $\mathrm{t}$ & Sig. \\
\hline (Constant) & 2,399 &, 020 \\
keaktifan & 11,275 &, 000 \\
\hline
\end{tabular}

Berdasarkan Tabel 4 diketahui bahwa nilai signifikansi pada variabel keaktifan sebesar $0<0,05$. Artinya bahwa keaktifan taruna di kelas berpengaruh secara signifikan terhadap nilai mata kuliah dasar-dasar akuntansi di Politeknik Bumi Akpelni.

c. Koefisien Determinasi $\left(\mathrm{R}^{2}\right)$

Berdasarkan hasil pengujian menunjukan bahwa nilai $\mathrm{R}^{2}$ sebesar 0,687 yang berarti bahwa variabel dependen yaitu nilai mata kuliah dasar-dasar akuntansi yang dapat di jelaskan oleh variabel independen dalam penelitian ini sebesar $68,7 \%$ sedangkan sisanya dijelaskan oleh variabel-variabel lain di luar model penelitian.

\section{Pembahasan Hasil Regresi Nilai Mata Kuliah Dasar-Dasar Akuntansi}

Berdasarkan hasil perhitungan di atas maka diketahui hasil analisis dari persamaan regresi:

Keterangan:

$$
y=0,777+0,844 x
$$

$y=$ nlai mata kuliah dasar-dasar akuntansi

$x=$ keaktifan taruna di kelas

Persamaan tersebut menunjukkan bahwa nilai koefisien $x$ sebesar 0,844 artinya apabila nilai keaktifan taruna di kelas $(x)$ meningkat 1 poin maka nilai mata kuliah dasar-dasar akuntansi $(y)$ akan meningkat sebesar 0,844 poin. 


\section{SIMPULAN}

Terdapat pengaruh keaktifan taruna di kelas terhadap nilai mata kuliah dasar-dasar akuntansi di Politeknik Bumi Akpelni. Nilai mata kuliah dasar-dasar akuntansi dipengaruhi oleh keaktifan taruna di kelas sebesar 68,7\%. Sedangkan 31,3\% dipengaruhi oleh faktor-faktor lainnya diluar penelitian ini. Bentuk keaktifan taruna ketika kegiatan perkuliahan dasar-dasar akuntansi antara lain: Taruna bertanya mengenai materi yang kurang dipahami, Taruna mampu menjawab pertanyaan-pertanyaan seputar materi yang diajarkan oleh dosen, Taruna mampu mengerjakan soal yang diberikan oleh dosen di papan tulis, Taruna aktif berdiskusi dengan taruna lainnya maupun dengan dosen mengenai materi perkuliahan.

\section{DAFTAR PUSTAKA}

Andika, K. F. dkk. 2018. Pengaruh Keaktifan Mahasiswa dalam Organisasi dan Prestasi Belajar terhadap Kesiapan Kerja Mahasiswa Program Studi Pendidikan Teknik Informatika dan Komputer Universitas Sebelas Maret Surakarta. Jurnal Ilmiah Edutic, 4 (2), hlm 1-11.

Astriawati, N. and Wibowo, W. (2019) 'Peningkatan Motivasi Dan Hasil Belajar Taruna Melalui Media Berbasis “Whiteboard Animation” Bidang Navigasi Pelayaran', Prosiding Konferensi Nasional Penelitian Dan Pembelajarannya IV, p. p-28. Available at: https://publikasiilmiah.ums.ac.id/handle/11617/11047.

Astriawati, N., Wibowo, W. and Pratama, W. (2019) 'Developing Mathematics Learning Materials Based on CO-PROL to Improve Cadets' Learning Outcomes', Journal of Physics: Conference Series. doi: 10.1088/17426596/1315/1/012059.

Irwanto. 2015. Pengaruh Gaya Mengajar Dosen, Asistensi dan Fasilitas BelajarTerhadap Prestasi Belajar Aplikasi Akuntansi Pemeriksaan. Jurnal Akuntansi Dan Sistem Teknologi Informasi, 11 (2), hlm. 243-250.

Muhibbidin Syah. 2015. Psikologi Belajar. Bandung: PT Remaja Rosdakarya.

Setyowati, D. 2016. Perbedaan Prestasi Belajar Mahasiswa Aktif Berorganisasi dengan Tidak Berorganisasi pada Program Studi Pendidikan Akuntansi FKIP UNS. Skripsi. Universitas Sebelas Maret, Surakarta.

Sugiyono. 2015. Metode Penelitian Pendidikan Pendekatan Kuantitatif, Kualitatif, dan $R \& D$. Bandung: CV Alfabeta. 